\title{
Examining the Impact of COVID-19 on Parental Stress: A Study of Foster Parents
}

\author{
J. Jay Miller ${ }^{1} \cdot$ Morgan E. Cooley $^{2} \cdot$ Brittany P. Mihalec-Adkins $^{3}$
}

Accepted: 4 November 2020 / Published online: 20 November 2020

(c) Springer Science+Business Media, LLC, part of Springer Nature 2020

\begin{abstract}
Purpose The overarching purpose of this exploratory study was to understand how foster parents' parenting-related stress levels have changed over the course of the COVID-19 pandemic, including the role of sociodemographic characteristics in exacerbating risk for increased stress.

Method Participants were electronically surveyed about their pre- and post-pandemic parenting-related stress, using an adapted version of the parenting stress scale.

Results Nine-hundred and ninety foster parents $(\mathrm{N}=990)$ participated in the study. Overall, foster parents reported significant increases along three specific domains of stress-namely, parenting stress, lack of control, and parental satisfaction (reversescored). Analyses for group differences on the post-only scores indicated that foster parents who are not married, or who report poorer mental health (i.e., "good", versus "very good" or "excellent") or financial circumstances (i.e., as indicated by not reliably having more income than expenses) may face increased risk for exacerbated stress during this pandemic.

Discussion Findings from this study indicate that parental stress-levels among foster parents have increased since the start of COVID-19. These findings are not only troubling for foster caregivers, but may also have implications for the youth in their care. Ultimately, results from this study indicate the need to better support foster parents, in general, and during public health crises, specifically.
\end{abstract}

Keywords Foster parents $\cdot$ Covid-19 $\cdot$ Coronavirus $\cdot$ Pandemic $\cdot$ Stress $\cdot$ Parental stress

\section{Introduction}

COVID-19 poses unique stressors to families, as well as cumulative risks that include social, economic, and healthrelated stressors (Prime et al., 2020). Findings from a rapidly evolving literature suggest that mental well-being is likely to be worse in those considered to be frontline workers, those with physical or mental health vulnerabilities, those who have direct experience with or proximity to someone with COVID-19, and children and parents (Nobles et al., 2020). There is evidence that the effects of social distancing may

J. Jay Miller

Justin.miller1@uky.edu

1 Self-Care Lab, College of Social Work, University of Kentucky, Lexington, USA

2 Phyllis and Harvey Sandler School of Social Work, Florida Atlantic University, Boca Raton, USA

3 Department of Human Development \& Family Studies, Purdue University, West Lafayette, USA have a more prominent impact on vulnerable groups of children and families, such as those with disabilities, underlying medical issues, or other types of social risk factorsincluding children in foster care or at risk of maltreatment (Dickinson \& Yates, 2020; Wong et al., 2020). In addition, there has been an increased reliance on women and families to provide extensive unpaid care to children due to social distancing measures and closures of schools and childcare facilities (Power, 2020).

Despite being prevalent in news stories, there is little research explicating the impact of COVID-19 on families, particularly regarding families providing foster care. However, foster care presents a unique context with uniquely complex challenges for foster parents and families (e.g., Thompson et al., 2019). This study investigated foster parent stress amidst the COVID-19 pandemic. Primary data were collected from foster parents $(N=990)$ in one state in the southeastern United States (U.S.) using the Parental Stress Scale (Berry \& Jones, 1995). To assess the impact of the COVID-19 pandemic on stress, researchers 
employed a retrospective pre/post design. Based on an exhaustive literature review, this paper appears to be the first that explicitly examines this issue. After a brief summation of relevant background information, this paper will present findings, discuss salient implications derived from the data, and identify apposite areas for future inquiry.

\section{COVID-19 Concerns Among Families Involved in the Child Welfare System}

There are a number of uncertainties among child welfare officials and families due to COVID-19; however, initial evidence has identified decreased child maltreatment reports in many states (Jonson-Reid et al., 2020; Welch \& Haskins, 2020). This trend has led to concerns about undetected issues of maltreatment that may lead to future problems for both families and child welfare systems. Despite guidelines and resources put forth by the Children's Bureau (2020) to address emerging concerns, and a number of news and opinion pieces (e.g., subscribe to CWIG, n.d. to receive daily news updates), there is relatively little empirically-based information available on how COVID-19 is impacting vulnerable children and families, and how the child welfare system is responding.

According to child welfare experts and news outlets, COVID-19 introduces serious risk into families, perhaps increasing opportunities or potential for maltreatment or subsequent child protective investigations, due to deficits related to meeting childcare demands, ensuring economic and food security, and receiving appropriate mental health or substance use services (Jonson-Reid et al., 2020; Kelly $\&$ Hansel, 2020). On the other hand, children and families formally involved in the child welfare or foster care systems may face issues related to accessing family visitation, reunification, court-mandated services, or timely court hearings; addressing the needs of youth with more significant mental or physical health needs; supporting foster families who are facing employment issues or conflicts in providing adequate care to youth due to COVID19 disruptions; supporting the physical health needs of older and immunocompromised foster caregivers; and addressing heightened risk for outbreaks in residential facilities (Golberstein et al., 2020; Goldman et al., 2020; Kelly \& Hansel, 2020). Others have identified that older foster youth or youth who recently "aged out" of foster care face additional risks to their employment, housing, or mental well-being due to COVID-19 (Greeson et al., 2020). The limited understanding of COVID-19 presents an emerging need for relevant scholarship to understand the potential impact on foster families and parents-the frontline workforce dedicated to caring for our most vulnerable children and youth.

\section{Foster Parent Stress within the Context of the Foster Care System}

As indicated, the foster care system presents a unique context and complex set of challenges for those involved (Thompson et al., 2019), and parenting or family life can look markedly different for foster families. Foster parents are tasked with providing care to children who have experienced a range of traumatic experiences, such as abuse, neglect, and separation from their primary caregiver or attachment figure, which predisposes children to subsequent mental health or behavioral difficulties (Greeson \& Pynoos, 2011). In turn, providing care to children with more prominent social, emotional, or behavioral needs can be challenging for foster parents (Cooley et al., 2015; Hebert \& Kulkin, 2018; Octomon \& McLean, 2014). Research has consistently noted that a number of foster parents feel underprepared to manage the mental health, diversity, and special needs of foster youth (Brown \& Rodger, 2009; Brown, et al., 2009; Cooley \& Petren, 2011). Recognizing these sources of stress may be particularly important, as foster parents who report higher compassion fatigue related to fostering also report lower fostering satisfaction and report being more likely to quit fostering, leading to placement disruptions (Hannah \& Woolgar, 2018). Additionally, foster parents may not always have the tools to manage this heightened stress; one recent study found that foster parents report only moderate engagement in self-care-and that self-care practices vary by gender, relationship status, health status, and financial status (Miller et al., 2019). Further, researchers have identified that foster parents also experience stress related to their interactions or experiences within the larger foster care system more broadly (Adams et al., 2018).

\section{A Systemic Perspective to Understanding the Potential Impact of COVID-19 on Foster Families}

Prime et al. (2020) reinforced that family risk and resilience must be understood systemically and reciprocally, particularly when dealing with acute stressors-like those brought about by the COVID-19 pandemic. They specifically argued that family risk is exacerbated during situations like a pandemic, which in turn impacts caregiver stress, family relationships, and child adjustment. Reciprocally, the level of individual and family functioning impacts the families' response to a pandemic. Social or environmental context, such as economic or social hardship, can intensify the disruption and risk/resilience trajectory of COVID-19 on families (Prime et al., 2020).

Although researchers have generally reported little evidence that foster parent stress has a negative reciprocal 
effect on foster child well-being (Goemans et al., 2015), there are relatively few studies that clearly explicate or even explore the impact of foster parent stress on the caregiver, child, or family system (Bergsund et al., 2019). However, multiple recent reports have found that foster parents report generally high levels of stress, outside of a crisis or emergency situation (e.g., Havik et al., 2016; Megahead \& Deater-Deckard, 2017), and some report higher levels of parental stress than biological parents in a natal family context (Bergsund et al., 2019). One thing does seem clear: foster care presents unique parenting circumstances, and whether the associated stress seems manageable or not, it is often present and must be coped with in some way (Adams et al., 2018; Cooley et al., 2017).

Another important consideration may be longstanding evidence that negative foster child behaviors and lower foster parent skill levels (i.e., the ability to manage child needs) are associated with foster placement breakdown (Konijn et al., 2019; Oosterman et al., 2007). Placement breakdown can be initiated by either the foster parent or agency when there are concerns that the child is faring poorly, and this dissolution is impactful or even harmful for the child and foster parent (e.g., Fisher et al., 2011; Newquist et al., 2020). Placement disruptions are arguably more problematic during the COVID-19 pandemic, as moving households introduces additional, novel risks related to virus spread. Considering the unique context of foster parenting and near-ubiquitous prevalence of foster parent stress, it is important to monitor the potential for COVID-19 to exacerbate that stress, which appears to have important systemic implications.

\section{Purpose}

The purpose of this study was to examine the impact of COVID-19 on parental stress among a sample of foster parents in one southeastern U.S. state. Specifically, this study was guided by the following research questions:

(1) Is there a significant difference in parental stress among foster parents between the time periods: (a) prior to the official declaration of COVID-19 as a pandemic, and (b) during the pandemic?

(2) Are there group-based differences in parental stress experienced during COVID-19, after controlling for pre-pandemic levels of stress?

The rationale for this study is strong. This paper addresses a dearth in the current literature as it relates to parental stress experienced during a pandemic. Given surges in COVID-19 cases as of October 2020 (see covid19.who.int), it is pertinent to conduct works that illuminate factors related to these surges. And, this study expands our current understanding of the parental stress literature. Findings from this research can inform responses to the needs of foster parents, conceptualization and implementation of stress management and support initiatives for foster parents, and inform policy guidance and adaptation associated with foster parenting during times of difficulty, such as a public health crisis.

\section{Methodology}

\section{Participants}

A total of 990 foster parents participated in this study. The mean age of participating foster parents was 41.94 years $(S D=10.61)$ and, at the time of the survey, participants housed an average of $1.94(S D=1.10)$ foster youth in their home. Additional demographic data is provided in Table 1 below.

\section{Recruitment and Data Collection Procedures}

Data for this study were collected during the spring of 2020. Purposive and snowball sampling were used to recruit licensed and currently active foster parents (i.e., inclusion criteria) who had not previously adopted a child (i.e., exclusion criteria). An initial survey invitation was sent to a widely-used foster parent listserv in the state of interest. Potential participants were asked to forward the invitation to other foster parents in < STATE REMOVED FOR BLIND REVIEW > who might be willing to participate. In appreciation for their time, participants had the opportunity to enter a drawing for one $\$ 500$ cash card. To ensure that participant responses remained anonymous, IP tracking was disabled and the primary survey link was disconnected from the link to opt-in for the incentive drawing.

Data were collected and managed using an online management system. The instruments included specific instructions for participants related to the Parental Stress Scale (PSS; instrument described below). Specifically, participants were asked to provide two ratings for each PSS item: one retrospectively/before the COVID-19 pandemic and another for their level of stress at the time they took the survey. For consistency, pre-pandemic was defined as PRIOR to March 11, 2020 (i.e., the date on which World Health Organization officially declared the COVID-19 outbreak a pandemic).

\section{Instrumentation}

\section{Demographic Characteristics}

To appropriately describe the sample, researchers asked participants to respond to a number of demographic and general queries regarding the following: Gender, Sexual Orientation, Race/Ethnicity, Current Relationship Status, Education 
Table 1 Demographic characteristics of participating foster parents $(\mathrm{N}=990)$

\begin{tabular}{|c|c|c|}
\hline & $N$ & $\%$ \\
\hline \multicolumn{3}{|l|}{ Gender } \\
\hline Male & 169 & 17.1 \\
\hline Female & 814 & 82.5 \\
\hline \multicolumn{3}{|l|}{ Sex orientation } \\
\hline Heterosexual or straight & 881 & 90.2 \\
\hline Gay or lesbian & 59 & 6.0 \\
\hline Bisexual & 19 & 1.9 \\
\hline Prefer not to answer & 18 & 1.8 \\
\hline \multicolumn{3}{|l|}{ Race/ethnic background } \\
\hline White non-Hispanic & 889 & 89.8 \\
\hline Black non-Hispanic & 75 & 7.6 \\
\hline American Indian or Alaskan Native & 6 & 0.6 \\
\hline Asian or Pacific Islander & 6 & 0.6 \\
\hline Hispanic & 11 & 1.1 \\
\hline \multicolumn{3}{|l|}{ Current relationship status ${ }^{\mathrm{a}}$} \\
\hline Married & 814 & 82.5 \\
\hline $\begin{array}{l}\text { Not married (partnered, separated, widowed, } \\
\text { divorced, \& never married) }\end{array}$ & 173 & 17.5 \\
\hline \multicolumn{3}{|l|}{ Highest academic degree } \\
\hline High school diploma or GED & 347 & 35.1 \\
\hline Associates & 190 & 19.2 \\
\hline Bachelor's & 219 & 22.1 \\
\hline Master's & 194 & 19.6 \\
\hline Doctorate & 31 & 3.1 \\
\hline I don't have an educational degree & 8 & 0.8 \\
\hline \multicolumn{3}{|l|}{ Employment status } \\
\hline Employed full-time & 594 & 60.1 \\
\hline Employed part-time & 98 & 9.9 \\
\hline Not employed & 225 & 22.8 \\
\hline Retired & 72 & 7.3 \\
\hline \multicolumn{3}{|l|}{ Physical health } \\
\hline Excellent & 185 & 18.7 \\
\hline Very good & 454 & 45.9 \\
\hline Good & 302 & 30.5 \\
\hline Fair & 49 & 4.9 \\
\hline \multicolumn{3}{|l|}{ Mental health } \\
\hline Excellent & 284 & 28.7 \\
\hline Very good & 484 & 48.9 \\
\hline Good & 222 & 22.4 \\
\hline Fair & N/A & N/A \\
\hline \multicolumn{3}{|l|}{ Current financial situation } \\
\hline Prefer not to answer & 112 & 11.3 \\
\hline I have just enough money to make ends meet & 88 & 8.9 \\
\hline I have enough money, with a little left over & 484 & 48.9 \\
\hline I always have money left over & 306 & 30.9 \\
\hline \multicolumn{3}{|l|}{ Biological children } \\
\hline Yes & 635 & 64.3 \\
\hline No & 352 & 35.7 \\
\hline No. of children currently living at home & & \\
\hline
\end{tabular}

Table 1 (continued)

\begin{tabular}{lll}
\hline & $N$ & $\%$ \\
\hline M & 2.93 & \\
SD & 3.11 & \\
Family structure & & \\
One parent household & 145 & 14.7 \\
Two parent household & 841 & 85.3 \\
\hline aOnly one participant per household participated in the study &
\end{tabular}

${ }^{\text {a } O n l y ~ o n e ~ p a r t i c i p a n t ~ p e r ~ h o u s e h o l d ~ p a r t i c i p a t e d ~ i n ~ t h e ~ s t u d y ~}$

Level, Current Financial Situation, and Employment Status (outside the home). Respondents were also asked to rate their physical and mental health, respectively.

\section{Foster Parent Parental Stress}

To assess parental stress, researchers utilized a version of the Parental Stress Scale (PSS; Berry \& Jones, 1995), with slight adaptations so as to refer specifically to foster parenting and foster children. The PSS is an 18-item self-report scale that includes positive aspects (e.g., self-enrichment, emotional benefits, personal development) and negative aspects (demands on resources, opportunity costs and restrictions) associated with parenting. There are four unique subscales: stressors (6 items; e.g., "The major source of stress in my life is my child(ren)"), loss of control (3 items; e.g., "I feel overwhelmed by the responsibility of being a parent"), satisfaction (3 items; e.g., "I am happy in my role as a parent"), and rewards (6 items; e.g., "I enjoy spending time with my children"). Each item is scored using a Likerttype scale anchored at 1 with "Strongly Disagree" and 5 with "Strongly Agree." Eight items are reverse scored. Total scores for the PSS can range between 18 and 90, with lower scores indicating lower stress levels. Cronbach's alpha for the total scale was $\alpha=0.89$; alphas for the subscales ranged from $0.81-0.89$.

\section{Data Analysis}

All data were entered into IBM SPSS 24 (SPSS, Inc., Chicago, IL), which was utilized for all data management and analyses. Overall, frequency distributions were first examined for the counts of observations in each response category of the instrument. Next, measures of central tendency (i.e., means and medians) and dispersion (i.e., range, minimum and maximum responses, and standard deviation) were calculated and investigated for data distribution patterns. Finally, to check for the assumptions of normality for analyses in the later stages, the numerical values of skewness and kurtosis were calculated for each of the variables of interest, using standards related to absolute values of the skewness statistics greater than \pm \pm 1 । 
(Ho \& Yu, 2014), and kurtosis statistics greater than $I \pm 2 \mid$ (Gravetter \& Wallnau, 2014). Based on these assessments, no severe deviation from normality was detected.

To assess changes in parental stress, researchers utilized a retrospective pre/post model. This approach entails administering one observational measure, and asking participants to endorse responses regarding a common variable for two distinct points in time, respectively. Though this approach to evaluation may be seldom employed, it is ideal for assessing variables related to events, such as the COVID-19 pandemic, that occur without notice or intent (i.e., where true "pre-event" assessments are not probable; e.g., Bhanji, Gottesman, de Grave, Steinert, \& Winer, 2012). Additional benefits of this approach include addressing inflated perceptions, thus eliminating the impact of response-shift bias and time efficiency (Geldhof, Warner, Finders, Thogmartin, Clark, \& Longway, 2018), among others. Paired-sample T-Tests (adjusted) were used to assess differences between pre and post scores. To assess group differences on post-scores for parental stress, researchers utilized ANCOVA analyses to control for effects on pre-scores.

Table 2 Pre- and post-COVID-19 PSS scores, by domain

\begin{tabular}{|c|c|c|c|c|}
\hline \multirow[t]{2}{*}{ Parental stress } & \multicolumn{2}{|c|}{$\begin{array}{l}\text { Pre COVID- } \\
19\end{array}$} & \multicolumn{2}{|c|}{$\begin{array}{l}\text { Post COVID- } \\
19\end{array}$} \\
\hline & $M$ & $S D$ & $M$ & $S D$ \\
\hline Total score & 34.86 & 9.97 & 35.54 & 10.83 \\
\hline Domain 1: parental stress (6-30) & 13.09 & 4.61 & 13.49 & 4.98 \\
\hline Domain 2: lack of control (4-20) & 9.23 & 2.90 & 9.42 & 3.09 \\
\hline Domain 3: parental satisfaction (4-20) & 6.26 & 2.16 & 6.44 & 2.41 \\
\hline Domain 4: parental reward (4-20) & 7.00 & 2.56 & 7.03 & 2.68 \\
\hline
\end{tabular}

Satisfaction has been reverse-coded, such that higher scores indicate less satisfaction (i.e., and are indicative of greater levels of this particular domain of parenting-related stress)

\section{Results}

Please note that for clarity and ease of reading, the second observation is referred to as measuring "Post-COVID-19" stress; however, we acknowledge that COVID-19 remains an ongoing pandemic at the time of this writing. Pre and post observations for PSS scores, by domain, are included in Table 2.

Results of paired-sample t-test are provided in Table 3 below. Analyses revealed significant, negative changes in three of the four PSS domains: Parental Stress, Lack of Control, and Parental Satisfaction.

Due to the exploratory nature of the study, one-way analyses of covariance (ANCOVA) were conducted to investigate possible unique impacts of key demographic categorical variables on the post-COVID-19 PSS scores, after controlling for pre-COVID-19 levels as covariates with the four domains, respectively. Significant differences in mean postCOVID-19 PSS scores were detected along three demographic/general variables: Marital Status, Current Financial Status, and Mental Health Status. Table 4 includes a summary of these results.

For Marital Status, responses were dichotomized at two levels: married vs. not married (i.e., partnered, separated, widowed, divorced, and never married). A significant main effect on post scores for Parental Stress $(F(1,1,183)=4.141$, $\left.p<0.05, \eta^{2}=0.003\right)$, Lack of Control $(F(1,1196)=6.765$, $\left.p<0.01, \eta^{2}=0.006\right)$ and Parental Satisfaction $(F(1$, $\left.1,192)=7.704, p<0.01, \eta^{2}=0.006\right)$ domains, respectively, after controlling for the covariance of the pre-scores.

Specifically, married foster parents $(M=13.41, S D=0.16)$ scored significantly lower on Parental Stress than those who were not married $(M=13.82, S D=0.34)$. For Lack of Con$\mathrm{trol}$, married foster parents $(M=9.35, S D=0.10)$ scored significantly lower than non-married foster parents $(M=9.72$, $S D=0.21)$. Similarly, married participants $(M=6.41$, $S D=0.08)$ scored significantly lower in Parental Satisfaction than did non-married participants $(M=6.60, S D=0.17)$.

As indicated in Table 4, Mental Health Status was selfreported as poor, fair, good, very good, or excellent. Since no participants reported "poor" or "fair" mental health, analysis
Table 3 Statistical comparisons of pre- and post-COVID-19 PSS levels, by domain

\begin{tabular}{lllll}
\hline Parental stress & Mean diff pre-post & SD & $t$-statistics & Effect size \\
\hline Total score & -.725 & 1.25 & -6.689 & .191 \\
Domain 1: parental stress & -.398 & 1.874 & $-7.323^{* * *}$ & .213 \\
Domain 2: lack of control & -.191 & 1.114 & $-5.940^{* * *}$ & .171 \\
Domain 3: parental satisfaction & -.185 & 1.138 & $-5.598^{* * *}$ & .158 \\
Domain 4: parental reward & -.028 & .995 & -.964 & .030 \\
\hline
\end{tabular}

Parental Satisfaction has been reverse-coded, such that higher scores indicate less satisfaction (i.e., and are indicative of greater levels of this particular domain of parenting-related stress); *** $p<.001$ 
Table 4 Summary of ANCOVA results for PSS scores

\begin{tabular}{|c|c|c|c|c|c|c|c|c|}
\hline \multirow[t]{2}{*}{ Parental stress domain } & \multicolumn{2}{|l|}{ Married } & \multicolumn{2}{|c|}{ Employment status } & \multicolumn{2}{|c|}{ Financial status } & \multicolumn{2}{|c|}{ Mental health } \\
\hline & $F$ & Effect size & $F$ & Effect size & $F$ & Effect size & $F$ & Effect size \\
\hline Domain 1: parental stress & $4.141^{*}$ & .003 & $3.608^{*}$ & .009 & 2.443 & .006 & $6.905 * *$ & .012 \\
\hline Domain 2: lack of control & $6.765 * *$ & .006 & $3.658^{*}$ & .009 & 2.457 & .006 & $5.337 * *$ & .009 \\
\hline Domain 3: parental satisfaction & $7.704 * *$ & .006 & $8.994 * * *$ & .022 & $3.516^{*}$ & .009 & $6.962 * *$ & .012 \\
\hline Domain 4: parental reward & 1.607 & .001 & 2.284 & .006 & 2.145 & .005 & $4.440 *$ & .007 \\
\hline
\end{tabular}

Parental Satisfaction has been reverse-coded, such that higher scores indicate less satisfaction (i.e., and are indicative of greater levels of this particular domain of parenting-related stress)

focused on comparing the other three response types. Significant main effects on post-scores were detected on the Parental Stress $\left(F(2,1,182)=6.905, p<0.01, \eta^{2}=0.012\right)$ Lack of Control $\left(F(2,1,195)=5.337, p<0.01, \eta^{2}=0.009\right)$, Parental Satisfaction $\left(F(2,1,190)=6.962, p<0.01, \eta^{2}=0.012\right)$, and Parental Reward $\left(F(2,1,183)=4.440, p<0.05, \eta^{2}=0.007\right)$ domains, respectively.

Participants who reported "excellent" mental health $(M=11.68, S D=0.26)$ scored significantly lower on Parental Stress when compared to those who reported "very good" $(M=13.66, S D=0.19)$ or "good" mental health $(M=15.26, S D=0.33)$. For Lack of Control, foster parents in "excellent" mental health $(M=8.27, S D=0.16)$ scored significantly lower than those reporting "very good" mental health $(M=9.51, S D=0.12)$ or "good" mental health. Foster parents who reported "excellent" mental health $(M=5.74$, $S D=0.12)$ scored significantly lower than those reporting "very good" $(M=6.43, S D=0.09)$ or "good" mental health $(M=7.30, S D=0.17)$ in Parental Satisfaction. In the area of Parental Reward, foster parents who reported "excellent" mental health $(M=6.50, S D=0.14)$ scored significantly lower than those who reported "very good" $(M=7.04$, $S D=0.11)$ and "good" mental health $(M=7.63, S D=0.17)$.

Analyses revealed significant effects for Current Financial Situation, after controlling for the covariance of the pre-pandemic PSS scores, $(F(3,1,191)=3.516, p<0.05$, $\left.\eta^{2}=0.009\right)$. Individuals who endorsed "I always have enough money left over" ( $M=6.21, S D=0.12)$ scored significantly lower in Parental Satisfaction (reverse-scored) that those who reported "I have enough money, with a little left over" $(M=6.40, S D=0.10)$, "I have just enough money to make ends meet" $(M=7.31, S D=0.25)$, or those who "Prefer not to answer" $(M=6.61, \mathrm{SD}=0.20)$, respectively.

\section{Discussion}

Comparing foster parents' parental stress before and after COVID-19 disruptions and accommodations were initiated, significant differences were detected across those who were not married, those with better mental health, and those with higher financial resources. Specifically, foster parents who were not married, those with poorer self-reported mental well-being, and those with fewer financial resources reported more negative change in parent stress when considering pre-COVID-19 and post-COVID-19 time points. Due to the lack of research on the impacts of COVID-19-particularly when it comes to impacts on those affected by foster care-as well as some limitations within prior foster care literature, the implications, limitations, and recommendations are discussed within a broader context of research literature. The findings appear to provide initial or preliminary support for the need to examine family risk and resilience systemically and contextually, as proposed by Prime and colleagues (2020), when conducting research on foster family functioning.

\section{Marital Status}

The results of this study indicate that married foster parents report less parenting-related stress during COVID-19 than those who are not married. Although there are no published studies specifically describing the context of marital status and foster parenting, particularly in the context of a global crisis like COVID-19, research among non-fostering single adults generally exhibits some level of disparity compared to those who are married. For example, researchers have noted that single individuals report generally lower life satisfaction than those in marriages or long-term partnerships (Gibney et al., 2017; Grover \& Helliwell, 2019; Stahnke et al., 2020), again, not accounting for the context or impact of a pandemic. Among single-parent biological mothers specifically, many have reported more frequent stressful life events and insufficient or deficient social support (Daryani et al., 2016; McBride-Murry et al., 2001). Further, single parents may have less time for more positive and high-quality interactions with children (e.g., Kendig \& Bianchi, 2008), which may lead to additional negative outcomes for child development or family functioning. Conversely, researchers have acknowledged a number of benefits that come with partnership or marriage, including lower rates of depression, higher life satisfaction, higher family satisfaction, more relatedness, 
and fewer "midlife crises" (e.g., Albert et al., 2010; Schafer et al., 2013; Vinson \& Ericson, 2014). Due to the closing of schools and childcare centers in response to COVID-19, women and families have faced a greater burden of providing unpaid full-time child care (Power, 2020) — a burden that would surely be exacerbated for single caregivers without a partner to share in the responsibilities. Taken together, research appears to support that the increased demands and acute impacts of social distancing measures in response to COVID-19 could apply disproportionate pressure on caregivers who are not married.

\section{Current Financial Status}

Outside of a pandemic, there are a number of groups who are more likely to experience financial strain. Specifically, single parents often report more emotional and financial strain than partnered caregivers (Glass et al., 2016), and single-parent households are more likely to experience poverty than twoparent households (e.g., Goodrum et al., 2012). In addition, grandparent and other relative caregivers have also reported higher levels of financial constraint compared to non-relative foster parents (Berrick \& Boyd, 2016). Findings from this study indicate that those with less financial insecurity are more likely to report higher levels of stress during COVID19. Financial insecurity has been associated with worse mental and physical health outcomes, as well as negative social and political outcomes (French \& Vigne, 2019; Sweet et al., 2013). Research has also suggested that financial insecurity is associated with decreased well-being for parents and children, particularly among low-income families (Ponnet, 2014). Considering each of these facets of prior research, compounded with the record-high unemployment rates due to COVID-19 (Kocchar, 2020), it would make sense that there are groups of foster parents who may be at higher risk of parental stress due to economic insecurity.

\section{Mental Health Status}

Although all participants in this study rated their mental well-being as being at least "good" (i.e., or "very good" or "excellent"), it is interesting to note that parent stress did increase post-COVID-19 among those reporting lessthan-excellent mental health. Due to the relative novelty of COVID-19, there is very limited research describing the mental health consequences thereof-and despite a growing number of articles commenting on this issue, many are still only commentaries or opinion pieces penned by health officials. However, there is some empirical evidence in Asian populations that COVID-19 has caused mental distress in both frontline (healthcare) workers and in the general population, but symptoms fall primarily below clinical, diagnostic levels for illness among 16-28\% of those screened (Rajkumar, 2020).

Perhaps because of the type and level of stress that foster parents routinely experience (Adams et al., 2018), it makes sense that parenting-related stress may be higher during the unique context of a pandemic - and particularly so for those who report less-than-excellent mental health to begin with. Prior foster care research supports that foster parents are susceptible to child-related stressors such as the negative impacts of parenting youth with behavioral problems (e.g., Goemans et al., 2015). Youth who have faced significant adversity including foster care, maltreatment, runaway experiences, or homelessness are at a higher risk than their peers for depression, self-harming behaviors, suicidal ideation, and suicide during normal times (Gewirtz O'Brien et al., 2020; Jonson-Reid et al., 2012). It is possible that the isolation or removal from positive environments or supports due to COVID-19 may impact youths' well-being (Cohen \& Bosk, 2020), which can exacerbate stress for foster families and have consequences for foster parents' stress and mental health. As indicated in the literature review, it is also important to consider the systemic nature of foster families and stress from unique stressors or crises (Prime et al., 2020). The interaction of foster parent stress, the potential strain put on family interactions when youth are unable to leave the house due to COVID-19-era restrictions, and the ways in which children adjust to sheltering in place is likely to have varying effects on families based upon their environmental or social context.

\section{Limitations}

Despite the large sample size, the results of this study should be interpreted in light of a few limitations. First, a portion of the survey administered was retrospective in nature, and therefore our analyses relied on foster parents' retrospective reports of pre-COVID-19 levels of stress, provided at the same time as their reports of their current levels of stress (i.e., post-COVID-19 levels). It is possible that foster parents have a different view or perspective of COVID-19 at this point in time compared to when they first started managing the effects of COVID-19 on their family's life (e.g., stress may be higher or lower as families work to adapt to the continued impact or context of the pandemic). Second, this study included a somewhat homogenous sample of foster parents who self-identified as mostly white and female; we acknowledge that a more diverse sample might have produced different or more nuanced results-particularly given the general acknowledgement that the COVID-19 pandemic disproportionately affects Black, Latinx, and other families of color. Third, while participants were informed that their responses were completely anonymous, there may be a 
response or selection bias in that foster parents may have felt some pressure to respond more positively, particularly in regard to mental health, or participants may have chosen to complete the study because they have not experienced significant effects from COVID-19.

\section{Recommendations}

Based on the findings and nature of this initial exploratory study, additional research is needed to delve into some of the murkier aspects of these findings and address the limitations of this survey. First, qualitative research is needed to better understand the context of foster parenting during a pandemic and to identify the specific types of stressors encountered and the lived consequences of each, as experienced by foster parents. Perhaps exacerbating stressors are driven primarily by individual characteristics (e.g., well-being or mental health), family dynamics and adjustment (e.g., strain on foster parent-child relationships or child adjustment), or factors of the larger social environment (e.g., lack of social or financial capital, state- and federal-level policies, schoolor child care-related changes, etc.). On the other hand, of course, it is also possible that the nature of stress experienced during COVID-19 is more complex or interactive, being exacerbated by multiple factors in varying ways across individuals, families, and communities. Second, it would be helpful to examine child-level outcomes associated with the pandemic, perhaps with an eye toward behavioral or physical health, to determine how foster youth are impacted-in both the short- and long-term. Such a study would also allow for some examination as to whether youths' physical or behavioral well-being - factors that are associated with subsequent negative outcomes, such as placement disruptions-are exacerbated during COVID-19, as well as how child-level characteristics moderate those risks. When examined with foster parent stress, additional interactions and moderators could be tested to examine the potential for reciprocal effects of foster parent stress and foster youth well-being.

Third and finally it would also be particularly important to identify what resources or supports have been most helpful for foster parents and youth in managing the impact of COVID-19 (e.g., Do foster parents need more parenting skills training, social support, or financial assistance during time of crisis?). Examining in-depth qualitative findings alongside quantitative indicators or interactions between foster parent stress and child outcomes could produce beneficial information regarding the specific types of resources or supports that are needed to better assist foster families. Over the course of the pandemic, there has been an unprecedented increase in reliance on telemedicine or tele-therapy services to address physical or behavioral health needs for children and families. Even after a vaccine that protects against
COVID-19 becomes widely available, it would be helpful to identify whether telehealth service delivery models are as effective as in-person services at meeting foster parent and youth needs, as the long-term implementation of such models may alleviate barriers to timely and continued support for foster parents and foster youth moving forward, in a system that is often stretch to capacity even in the absence of a pandemic.

\section{Conclusion}

Overall, results of this exploratory study indicate that foster parents reported increases in stress during the COVID-19 pandemic, along three distinct dimensions: parenting-related stressors, lack of control, and parenting-related satisfaction. Further, results suggest that foster parents who are not married, who report less-than-excellent mental health, and who report more financial constraint face increased risks for heightened parenting-related stress during this pandemic. Future efforts should focus on qualitatively examining the experience of fostering during the COVID-19 pandemic, identifying additional individual-, family-, and communitylevel risk factors for exacerbated stress, and understanding the resulting child-level consequences of experiencing foster placement—and heightened foster parent stress—during a pandemic.

\section{References}

Adams, E., Hassett, A. R., \& Lumsden, V. (2018). What do we know about the impact of stress on foster carers and contributing factors? Adoption \& Fostering, 42, 338-353. https://doi. org/10.1177/0308575918799956.

Albert, I., Labs, K., \& Trommsdorff, G. (2010). Are older adult German women satisfied with their lives?: On the role of life domains, partnership status, and self-construal. GeroPsych: The Journal of Gerontopsychology and Geriatric Psychiatry, 23, 39-49. https:// doi.org/10.1024/1662-9647/a000002.

Bergsund, H. B., Wentzel-Larsen, T., \& Jacobsen, H. (2019). Parenting stress in long-term foster carers: A longitudinal study. Child \& Family Social Work, Advance Online. https://doi.org/10.1111/ cfs. 12713.

Berrick, J. D., \& Boyd, R. (2016). Financial well-being in familybased foster care: Exploring variation in income supports for kin and non-kin caregivers in California. Children and Youth Services Review, 69, 166-173. https://doi.org/10.1016/j.childyouth .2016.08.011.

Berry, J. O., \& Jones, W. H. (1995). The Parental Stress Scale: Initial psychometric evidence. Journal of Social and Personal Relationships, 12(3), 463-472.

Bhanji, F., Gottesman, R., de Grave, W., Steinert, Y., \& Winer, L. (2012). The retrospective pre-post: A practical method to evaluate learning from an educational program. Academy Emergency Medicine, 19(2), 189-194. https://doi.org/10.111 $1 / \mathrm{j} .1553-2712.2011 .01270 . x$. 
Brown, J. D., \& Rodger, S. (2009). Children with disabilities: Problems faced by foster parents. Children and Youth Services Review, 31, 40-46. https://doi.org/10.1016/j.childyouth.2008.05.007.

Brown, J. D., St. Arnault, D., George, N., \& Sintzel, J. (2009). Challenges of transcultural placements: Foster parent perspectives. Child Welfare, 88, 103-126.

Children's Bureau. (2020). COVID-19 resources. https://www.acf.hhs. gov/cb/resource/covid-19-resources

Child Welfare Information Gateway (CWIG). (n.d.). Sign up \& stay connected! https://public.govdelivery.com/accounts/USACF CWIG/subscriber/new?preferences=true\#tab1

Cohen, R. S., \& Bosk, E. A. (2020). Vulnerable youth and the COVID19 pandemic. Pediatrics, 146, e20201306. https://doi.org/10.1542/ peds.2020-1306.

Cooley, M. E., Farineau, H. M., \& Mullis, A. K. (2015). Child behaviors as a moderator: Examining the relationship between foster parent supports, satisfaction, and intent to continue fostering. Child Abuse \& Neglect, 45, 46-56. https://doi.org/10.1016/j.chiab u.2015.05.007.

Cooley, M. E., \& Petren, R. E. (2011). Foster parent perceptions of competency: Implications for foster parent training. Children and Youth Services Review, 33, 1968-1974. https://doi.org/10.1016/j. childyouth.2011.05.023.

Cooley, M. E., Thompson, H. M., \& Wojciak, A. S. (2017). Risk, resilience, and complexity: Experiences of foster parents. Children and Youth Services Review, 76, 34-41. https://doi.org/10.1016/j. childyouth.2017.02.030.

Daryani, I., Hamilton, J. L., Abramson, L. Y., \& Alloy, L. B. (2016). Single mother parenting and adolescent psychopathology. Journal of Abnormal Child Psychology, 44(7), 1411-1423. https://doi. org/10.1007/s10802-016-0128-x.

Dickinson, H., \& Yates, S. (2020). More than isolated: The experience of children and young people with disability and their families during the COVID-19 pandemic. Melbourne, Australia: Children and Young People with Disability Australia (CYDA).

Fisher, P. A., Stoolmiller, M., Mannering, A. M., Takahashi, A., \& Chamberlain, P. (2011). Foster placement disruptions associated with problem behavior: Mitigating a threshold effect. Journal of Consulting and Clinical Psychology, 79, 481-487. https://doi. org/10.1037/a0024313.

French, D., \& Vigne, S. (2019). The causes and consequences of household financial strain: A systematic review. International Review of Financial Analysis, 62, 150-156. https://doi.org/10.1016/j. irfa.2018.09.008.

Geldhof, G., Warner, D., Finders, J., Thogmartin, A., Clark, A., \& Longway, K. (2018). Revisiting the utility of retrospective prepost designs: the need for mixed-method pilot data. Evaluation \& Program Planning, 70, 83-89.

Gewirtz O’Brien, J. R., Edinburgh, L. D., Barnes, A. J., \& McRee, A. L. (2020). Mental health outcomes among homeless, runaway, and stably housed youth. Pediatrics, 145(4), e20192674. https://doi. org/10.1542/peds.2019-2674.

Gibney, S., Delaney, L., Codd, M., \& Fahey, T. (2017). Lifetime childlessness, depressive mood and quality of life among older Europeans. Social Indicators Research, 130, 305-323. https://doi. org/10.1007/s11205-015-1177-1.

Glass, J., Simon, R. W., \& Andersson, M. A. (2016). Parenthood and happiness: Effects of work-family reconciliation policies in 22 OECD countries. American Journal of Sociology, 122(3), 886929. https://doi.org/10.1086/688892.

Goemans, A., van Geel, M., \& Vedder, P. (2015). Over three decades of longitudinal research on the development of foster children: A meta-analysis. Child Abuse \& Neglect, 42, 121-134. https://doi. org/10.1016/j.chiabu.2015.02.003.

Golberstein, E., Wen, H., \& Miller, B. F. (2020). Coronavirus disease 2019 (COVID-19) and mental health for children and adolescents.
Journal of the American Medical Association, Online. https://doi. org/10.1001/jamapediatrics.2020.1456.

Goldman, P. S., van Ijzendoorn, M. H., \& Sonuga-Barke, E. J. (2020). The implications of COVID-19 for the care of children living in residential institutions. The Lancet, 4, E12. https://doi. org/10.1016/S2352-4642(20)30130-9.

Goodrum, N. M., Jones, D. J., Kincaid, C. Y., Cuellar, J., \& Parent, J. M. (2012). Youth externalizing problems in African American single-mother families: A culturally relevant model. Couple and Family Psychology: Research and Practice, 1(4), 294-305. https ://doi.org/10.1037/a0029421.

Gravetter, F. \& Wallnau, L. (2014). Essentials of statistics for the behavioral sciences. 8th Edition, Wadsworth, Belmont, CA.

Greeson, J. K., \& Pynoos, R. S. (2011). Complex trauma and mental health in children and adolescents placed in foster care: Findings from the national child traumatic stress network. Child Welfare, 90, 91-108.

Greeson, J., Jaffee, S., \& Wasch, S. (2020). The experiences of foster youth during COVID-19. APSAC Alert, 11(5), 1-3.

Grover, S., \& Helliwell, J. F. (2019). How's life at home? New evidence on marriage and the set point for happiness. Journal of Happiness Studies: An Interdisciplinary Forum on Subjective Well-Being, 20, 373-390. https://doi.org/10.1007/s10902-017-9941-3.

Hannah, B., \& Woolgar, M. (2018). Secondary trauma and compassion fatigue in foster carers. Clinical Child Psychology and Psychiatry, 23, 629-643. https://doi.org/10.1177/1359104518778327.

Havik, T., Jacobsen, H., \& Lehmann, S. (2016). Gruppeveiledning for nye fosterforeldre: En evaluering, på vei mot en kunnskapsbasert praksis [Group support for new foster parents]. Oslo: Center for Child and Adolescent Mental Health.

Hebert, C. G., \& Kulkin, H. (2018). An investigation of foster parent training needs. Child \& Family Social Work, 23, 256-263. https ://doi.org/10.1111/cfs.12413.

Ho, A. D., \& C. C. Yu. (2014). Descriptive statistics for modern test score distributions: Skewness, kurtosis, discreteness, and ceiling effects. Educational and Psychological Measurement, 75(3), 365-388.

Jonson-Reid, M., Drake, B., Cobetto, C., \& Ocampo, M. G. (2020). Child abuse prevention month in the context of COVID-19. St Louis, MO: Center for Innovation in Child Maltreatment Policy, Research and Training, Washington University in St. Louis.

Jonson-Reid, M., Kohl, P. L., \& Drake, B. (2012). Child and adult outcomes of chronic child maltreatment. Pediatrics, 129(5), 839-845. https://doi.org/10.1542/peds.2011-2529.

Kelly, J., \& Hansel, K. (2020, March 11). Coronavirus: What child welfare systems need to think about. The Chronicle of Social Change. https://chronicleofsocialchange.org/child-welfare-2/coronaviru s-what-child-welfare-systems-need-to-think-about/41220

Kendig, S. M., \& Bianchi, S. M. (2008). Single, cohabitating, and married mother's time with children. Journal of Marriage and Family, 70(5), 1128-1240. https://doi.org/10.111 1/j.1741-3737.2008.00562.x.

Kocchar, R. (2020). Unemployment rose higher in three months of COVID-19 than it did in two years of the Great Recession. Washington, DC: Pew Research Center. https://www.pewresearch.org/ fact-tank/2020/06/11/unemployment-rose-higher-in-three-month s-of-covid-19-than-it-did-in-two-years-of-the-great-recession/

Konijn, C., Admiraal, S., Baart, J., van Rooij, F. B., Stams, G. J. J. M., Colonnesi, C., Lindauer, R. J. L., \& Assink, M. (2019). Foster care placement instability: A meta-analytic review. Children and Youth Services Review, 96, 483-499.

McBride-Murry, V., Bynum, M. S., Brody, G. H., Willert, A., \& Stephens, D. (2001). African American single mothers and children in context: a review on studies of risk and resilience. Clinical Child and Family Psychology Review, 4, 133-155. https://doi. org/10.1023/A:1011381114782. 
Megahead, H. A., \& Deater-Deckard, K. (2017). Parenting stress and foster children's adjustment in an Egyptian context. Journal of Child and Family Studies, 26, 2266-2275. https://doi.org/10.1007/ s10826-017-0736-2.

Miller, J., Cooley, M., Owens, L., \& Fletcher, J. (2019). Self-care practices among foster parents: An exploratory study. Children and Youth Services Review, 98, 206-212. https://doi.org/10.1016/j. childyouth.2019.01.002.

Newquist, J., Ladd, L. D., \& Cooley, M. E. (2020). Processing the removal and managing the moves or removals of foster children: A qualitative exploration of foster parents' experiences. Child \& Adolescent Social Work, Advance Online. https://doi.org/10.1007/ s10560-020-00652-w.

Nobles, J., Martin, F., Dawson, S., Moran, P., \& Savovic, J. (2020). The potential impact of COVID-19 on mental health outcomes and the implications for service solutions. Bristol, UK: National Institute for Health Research.

Octoman, O., \& McLean, S. (2014). Challenging behaviour in foster care: What supports do foster parents want? Adoption \& Fostering, 38, 149-158. https://doi.org/10.1177/0308575914532404.

Oosterman M., Schuengel C., Slot N. W., Bullens R. A. R., \& Doreleijers T. A. H. (2007). Disruptions in foster care: A review and meta-analysis. Children and Youth Services Review, 29, 53-76. https://doi.org/10.1016/j.childyouth.2006.07.003.

Ponnet, K. (2014). Financial stress, parent functioning and adolescent problem behavior: An actor-partner interdependence approach to family stress processes in low-, middle-, and high-income families. Journal of Youth and Adolescence, 43, 1752-1769. https:// doi.org/10.1007/s10964-014-0159-y.

Power, K. (2020). The COVID-19 pandemic has increased the care burden of women and families. Sustainability: Science Practice and Policy, 16, 67-73. https://doi.org/10.1080/15487733.2020.17765 61.

Prime, H., Wade, M., \& Browne, D. T. (2020). Risk and resilience in family well-being during the COVID-19 pandemic. American Psychologist. https://doi.org/10.1037/amp0000660.
Rajkumar, R. P. (2020). COVID-19 and mental health: A review of the existing literature. Asian Journal of Psychiatry. https://doi. org/10.1016/j.ajp.2020.102066.

Schafer, M. H., Mustillo, S. A., \& Ferraro, K. F. (2013). Age and the tenses of life satisfaction. The Journals of Gerontology: Series B: Psychological Sciences and Social Sciences, 68, 571-579. https:// doi.org/10.1093/geronb/gbt038.

Stahnke, B., Blackstone, A., \& Howard, H. (2020). Lived experiences and life satisfaction of childfree women in late life. The Family Journal. https://doi.org/10.1177/1066480720911611.

Sweet, E., Nandib, A., Adam, E. K., \& McDade, T. W. (2013). The high price of debt: Household financial debt and its impact on mental and physical health. Social Science \& Medicine, 91, 94-100. https ://doi.org/10.1016/j.socscimed.2013.05.009.

Thompson, H. M., Wojciak, A. S., \& Cooley, M. E. (2019). Familybased approach to the child welfare system: An integration of Bowen family theory concepts. Journal of Family Social Work, 3 , 231-252. https://doi.org/10.1080/10522158.2019.1584776.

Vinson, T., \& Ericson, M. (2014). The social dimensions of happiness and life satisfaction of Australians: Evidence from the world values survey. International Journal of Social Welfare, 23, 240-253. https://doi.org/10.1111/ijsw.12062.

Welch, M., \& Haskins, R. (2020). What COVID-19 means for America's child welfare system. Washington, DC: Brookings Institute. https://www.brookings.edu/research/what-covid-19-means-foramericas-child-welfare-system/

Wong, C. A., Ming, D., Maslow, G., \& Gifford, E. J. (2020). Mitigating the impacts of the COVID-19 pandemic response on at-risk children. Pediatrics. https://doi.org/10.1542/peds.2020-0973.

Publisher's Note Springer Nature remains neutral with regard to jurisdictional claims in published maps and institutional affiliations. 